\title{
Building A Large Chinese Corpus Annotated With Semantic Dependency
}

\author{
LI Mingqin \\ Department of Electronic Engineering, \\ Tsinghua University, \\ Beijing 100084, China \\ lmq@thsp.ee.tsinghua \\ .edu.cn
}

WANG Zuoying

Department of Electronic Engineering,

Tsinghua University, Beijing 100084, China

wzy-dee@tsinghua.edu.cn

\author{
DONG Zhendong \\ Research Centre of Computer \& \\ Language Engineering, \\ Chinese Academy of Sciences, \\ Beijing, 100084,China \\ dzd@keenage.com
}

\author{
LU Dajin \\ Department of Electronic Engineering, \\ Tsinghua University, \\ Beijing 100084, China \\ ludj@mail.tsinghua.edu.cn
}

\begin{abstract}
At present most of corpora are annotated mainly with syntactic knowledge. In this paper, we attempt to build a large corpus and annotate semantic knowledge with dependency grammar. We believe that words are the basic units of semantics, and the structure and meaning of a sentence consist mainly of a series of semantic dependencies between individual words. A 1,000,000-wordscale corpus annotated with semantic dependency has been built. Compared with syntactic knowledge, semantic knowledge is more difficult to annotate, for ambiguity problem is more serious. In the paper, the strategy to improve consistency is addressed, and congruence is defined to measure the consistency of tagged corpus.. Finally, we will compare our corpus with other well-known corpora.
\end{abstract}

\section{Introduction}

As basic research tools for investigators in natural language processing, large annotated corpora play an important role in investigating diverse language phenomena, building statistical language models, evaluating and comparing kinds of parsing models. At present most of corpora are annotated mainly with syntactic knowledge, though some function tags are added to annotate semantic knowledge. For example, the Penn Treebank (Marcus et al., 1993) was annotated with skeletal syntactic structure, and many syntactic parsers were evaluated and compared on the corpus. For Chinese, some corpora annotated with phrase structure also have been built, for instance the Penn Chinese Treebank (Xia et al., 2000) and Sina Corpus (Huang and Chen, 1992). A syntactic annotation scheme based on dependency was proposed by (Lai and Huang, 2000), and a small corpus was built for testing. However, very limited work has been done with annotation semantic knowledge in all languages. From 1999, Berkeley started FrameNet project (Baker et al., 1998), which produced the frame-semantic descriptions of several thousand English lexical items and backed up these description with semantically annotated attestations from contemporary English corpus. Although few corpora annotated with semantic knowledge are available now, there are some valuable lexical databases describing the lexical semantics in dictionary form, for example English WordNet (Miller et al., 1993) and Chinese HowNet (Dong and Dong, 2001).

For Chinese, many attentions have been naturally paid to researches on semantics, because Chinese is a meaning-combined language, its syntax is very flexible, and semantic rules are more 
stable than syntactic rules. For instance, in Chinese it is very pervasive that more than one part-of -speeches a word has, and a word does not have tense or voice flectional transition under different tenses or voices. Nevertheless, no large Chinese corpus annotated with semantic knowledge has ever been built at present. In Semantic Dependency Net (SDN), we try to describe deeper semantic dependency relationship between individual words and represent the meaning and structure of a sentence by these dependencies.

Compared with syntactic corpus, it is more difficult to build a semantic corpus, for the granularity of semantic knowledge is smaller, and behaviors of different words differ more greatly. Furthermore, ambiguity in semantics is commoner. Different people may have different opinions on understanding the same word in the same sentence, and even the same people may have different opinions on understanding the same word in different occasions. In this paper, we emphatically discuss the strategy to improve the consistency of Semantic Dependency Net.

The paper is organized as follows. The tagging scheme is discussed in Section 2, which describes the semantic dependency grammar and the tag set of semantic relations. In section 3 , we describe the tagging task. First, we briefly introduce the text of this corpus, which has been tagged with semantic classes. Second, we describe the strategy to improve consistency during tagging and checking. At last, congruence is defined to measure the consistency of tagged corpus. In Section 4, we briefly introduce some of the works on the corpus, and indicate the directions that the project is likely to take in the future. Finally, we compare SDN corpus with some other well-known corpora.

Chinese: 㑊/Dd15 博士/Ae13 近年来/Ca11 十分/Ka01 重视/Gb21 其/Aa04 发明/Hc05 成果/Da14 的/Kd01 推广/Ie01 使用/Hj28

English: These years, Doctor Yang pays a lot of attention to the popularization and application of his invention.

(a)

\begin{tabular}{|c|c|c|c|c|}
\hline \multicolumn{2}{|r|}{ Modifier } & \multicolumn{2}{|r|}{ HeadWord } & \multirow{2}{*}{ Semantic Relation } \\
\hline Index & Word & Index & Word & \\
\hline 0 & 杨/Yang & 1 & 博士/Doctor & 限定/Restrictive \\
\hline 1 & 博士/Doctor & 4 & 重视/pay attention to & 经验者/Experiencer \\
\hline 2 & 近年来/these years & 4 & 重视/pay attention to & 时间/Time \\
\hline 3 & 十分/a lot & 4 & 重视/pay attention to & 程度/Degree \\
\hline 4 & 重视/pay attention to & -1 & -1 & 核心成分/Kernel word \\
\hline 5 & 其/his & 7 & 成果/production & 限定/Restrictive \\
\hline 6 & 发明/invention & 7 & 成果/production & 限定/Restrictive \\
\hline 7 & 成果/production & 9 & 推广/popularization & 内容/Content \\
\hline 8 & 的/of & 7 & 成果/product & “的”字依存/ 'De' dependency \\
\hline 9 & 推广/popularization & 4 & 重视/pay attention to & 目标/Target \\
\hline 10 & 使用/application & 9 & 推广/popularization & 连接/Connection \\
\hline
\end{tabular}

(b)

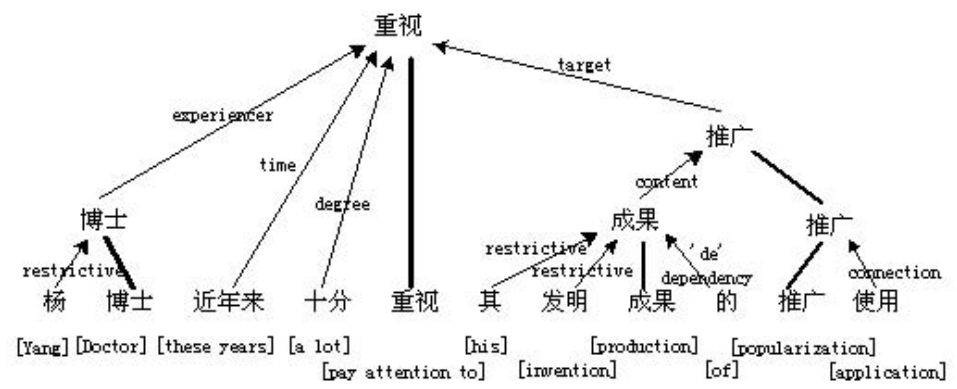

(c)

Figure 1: A sample sentence from the corpus. (a) The sentence tagged with semantic classes; (b) The sentence annotated with semantic dependency; (c) The semantic dependency tree of the sentence, headwords are linked with bold lines, and modifier words are linked with arrow lines. 


\section{The tagging scheme of semantic depend- ency}

\subsection{Semantic dependency grammar}

Like Word grammar (Hudson, 1998), We believe that words are the basic units of semantics, and the structure and meaning of a sentence consist mainly of semantic dependencies between individual words. So a sentence could be annotated with a series of semantic dependency relations $(\mathrm{Li}$ Juanzi and Wang, 2002). Let $S$ be a sentence composed of words tagged with semantic classes, $S=\left\{<w_{1}, s_{1}>,<w_{2}, s_{2}>, \cdots,<w_{n}, s_{n}>\right\}$. A list of semantic dependency relations is defined as: $S R L=\{S R(1), S R(2), \cdots, S R(n)\}$

where $S R(i)=\left(h_{i}, r_{i}\right)$. SR stands for " semantic relation'. $S R(i)=\left(h_{i}, r_{i}\right)$ states that the $h_{i}$-th word is the headword to the $\mathrm{i}$-th word with semantic relation $r_{i}$. If the word $\mathrm{j}$ is the root, $S R(j)$ is defined to be (-1, "kernel word").

For example, a sample sentence from the corpus is shown in Figure 1 (a). The semantic dependency relation list and semantic dependency tree are shown in Figure 1 (b) and (c) respectively. More samples will be seen in Appendix A.

In semantic dependency grammar, the headword of sentence represents the main meaning of the whole sentence, and the headword of constituent represents the main meaning of the constituent. In a compound constituent, the headword inherits the headword of the head sub-constituent, and headwords of other sub-constituents are dependent on that headword. We select the word that can represent the meaning of the constituent to the most extent as headword. For example, the verb is the headword of verb phrase, the object is the headword of preposition phrase, and the location noun is the headword of the location phrase.

At the same time, semantic dependency relations do not damage the phrase structure, that is, all words in the same phrase are in the same subtree whose root is the headword of the phrase. Therefore, when tagging dependency relations, semantic and syntactic restrictions are both taken into account. The structures of dependency tree are mainly determined by syntactic restrictions, and the semantic relations are mainly determined by semantic restrictions. For example, in Figure 1 the phrase “其发明成果的”( of his invention production) modifies the phrase “推广使用” (popularization and application) in syntax, so the word “推广” (popularization) governs the word “成果” (production). However, the production is the content of the action popularization in semantics, so the relation between them is "content".

Our tagging scheme is more concise compared with phrase structure grammar, in which the boundaries of all phrases have to be marked and the corresponding labels have to be tagged. In the semantic dependency grammar, phrases are implicit, but play no part in grammar. More emphasis is paid to the syntactic and semantic functions of the word, especially of the headword.

\subsection{The dependency relation tag set}

The dependency relation tag set mainly consists of three kinds of relations: semantic relations, syntactic relations and special relations. Semantics is the main content of this corpus, so semantic relations are in the majority, and syntactic relations are used to annotate the special structures that do not have exact sense in terms of semantics. In addition, there are two special relations: "kernel word" is to indicate the headword of a sentence, and "failure" is to indicate the word that cannot be annotated with dependency relations because the sentence is not completed.

The selections of semantic relations were referred to HowNet (Dong and Dong, 2001). HowNet is a lexical database, which describes the relations among words and concepts as a network. In HowNet, senventy-six semantic relations are defined to describe all relations among various concepts, and most of them describe the semantic relations between action and other concepts. With these semantic relations, necessary role frame is further defined. The roles in the necessary role frame must take part in the action in real word, while these roles may not appear in the same sentence. Hong Kong Technology University has successfully tagged a news corpus with the necessary role frame (Yan and Tan, 1999), which shows that these roles can describe all semantic phenomena in real texts.

In order to make tagging task easier and the corpus more suitable for statistical learning, we have pared down some relations in HowNet and 
got fifty-nine semantic relations. Some HowNet relations seldom occurred in the corpus, and their semantic functions are somewhat similar, so they are merged. Some relations are ambiguous, for example "degree" and "range". In order to improve the consistency, we also merge these two relations.
Semantic relations can describe the relations between notional words, but they cannot annotate function words in some special phrase structures. So nine syntactic relations are added.

The tag set is listed in table 1. Full definition of each dependency relation can be seen in $(\mathrm{Li}$ Mingqin et al., 2002).

\begin{tabular}{|c|c|c|c|c|c|c|}
\hline \multirow{11}{*}{$\begin{array}{l}\text { Semantic } \\
\text { Relations } \\
\quad \text { (59) }\end{array}$} & $\begin{array}{l}\text { Relevant } \\
\text { /关系主体 }\end{array}$ & $\begin{array}{l}\text { Possessor } \\
\text { /领有者 }\end{array}$ & $\begin{array}{l}\text { Existent } \\
\text { /存现体 }\end{array}$ & $\begin{array}{l}\text { Experiencer } \\
\text { /经验者 }\end{array}$ & $\begin{array}{l}\text { Agent } \\
\text { /施事 }\end{array}$ & $\begin{array}{c}\text { Descriptive } \\
\text { /描写体 }\end{array}$ \\
\hline & $\begin{array}{l}\text { Possession } \\
\text { /占有物 }\end{array}$ & $\begin{array}{l}\text { Patient } \\
\text { /受事 }\end{array}$ & $\begin{array}{l}\text { Part0fTouch } \\
\text { /触及部件 }\end{array}$ & $\begin{array}{l}\text { Content } \\
\text { /内容 }\end{array}$ & $\begin{array}{l}\text { Isa } \\
\text { /类指 }\end{array}$ & $\begin{array}{l}\text { Part0f } \\
\text { /部分 }\end{array}$ \\
\hline & $\begin{array}{l}\text { Whole } \\
\text { /整体 }\end{array}$ & $\begin{array}{l}\text { Result } \\
\text { /结果 }\end{array}$ & $\begin{array}{l}\text { Target } \\
\text { /月标 }\end{array}$ & $\begin{array}{l}\text { Cost } \\
\text { /代价 }\end{array}$ & $\begin{array}{l}\text { Resu1tEvent } \\
\text { /结果事件 }\end{array}$ & $\begin{array}{l}\text { EventProcess } \\
\text { /事件过程 }\end{array}$ \\
\hline & $\begin{array}{l}\text { Succeeding } \\
\text { /接续 }\end{array}$ & $\begin{array}{l}\text { Accompaniment } \\
\text { /伴随 }\end{array}$ & $\begin{array}{l}\text { Modifier } \\
\text { /描述 }\end{array}$ & $\begin{array}{l}\text { Restrictive } \\
\text { /限定 }\end{array}$ & $\begin{array}{l}\text { Quantity } \\
\text { /数量 }\end{array}$ & $\begin{array}{l}\text { Appositive } \\
\text { /同位语 }\end{array}$ \\
\hline & $\begin{array}{l}\text { Degree } \\
\text { /程度 }\end{array}$ & $\begin{array}{l}\text { Manner } \\
\text { /方式 }\end{array}$ & $\begin{array}{l}\text { Frequency } \\
\text { /频率 }\end{array}$ & $\begin{array}{l}\text { Times } \\
\text { /动量 }\end{array}$ & $\begin{array}{l}\text { Scope } \\
\text { /范围 }\end{array}$ & $\begin{array}{l}\text { Comment } \\
\text { / 评论 }\end{array}$ \\
\hline & $\begin{array}{l}\text { Time } \\
\text { /时间 }\end{array}$ & $\begin{array}{l}\text { TimeIni } \\
\text { /起始时间 }\end{array}$ & $\begin{array}{l}\text { TimeFin } \\
\text { /终止时间 }\end{array}$ & $\begin{array}{l}\text { DurationAf terEvent } \\
\text { /后延时段 }\end{array}$ & $\begin{array}{l}\text { Duration } \\
\text { /进程时段 }\end{array}$ & $\begin{array}{l}\text { Time } \\
\text { /时间 }\end{array}$ \\
\hline & $\begin{array}{l}\text { TimeIni } \\
\text { /起始时间 }\end{array}$ & $\begin{array}{l}\text { TimeFin } \\
\text { /终止时间 }\end{array}$ & $\begin{array}{l}\text { Duration } \\
\text { /进程时段 }\end{array}$ & $\begin{array}{c}\text { DurationAfterEvent } \\
\text { /后延时段 }\end{array}$ & $\begin{array}{l}\text { TimeRange } \\
\text { /时距 }\end{array}$ & $\begin{array}{l}\text { Location } \\
\text { / 处所 }\end{array}$ \\
\hline & $\begin{array}{l}\text { LocationIni } \\
\text { /原处所 }\end{array}$ & $\begin{array}{l}\text { LocationFin } \\
\text { /终处所 }\end{array}$ & $\begin{array}{l}\text { LocationThru } \\
\text { /通过处所 }\end{array}$ & $\begin{array}{c}\text { StateIni } \\
\text { /原状态 }\end{array}$ & $\begin{array}{l}\text { StateFin } \\
\text { /终状态 }\end{array}$ & $\begin{array}{l}\text { Partner } \\
\text { /相伴体 }\end{array}$ \\
\hline & $\begin{array}{l}\text { Contrast } \\
\text { /参照体 }\end{array}$ & $\begin{array}{l}\text { ContentCompare } \\
\text { /比较内容 }\end{array}$ & $\begin{array}{l}\text { QuantityCompare } \\
\text { /比较量 }\end{array}$ & $\begin{array}{l}\text { Means } \\
\text { /手段 }\end{array}$ & $\begin{array}{l}\text { Instrument } \\
\text { /工具 }\end{array}$ & $\begin{array}{l}\text { Material } \\
\text { / 材料 }\end{array}$ \\
\hline & $\begin{array}{l}\text { Source } \\
\text { /来源 }\end{array}$ & $\begin{array}{l}\text { Cause } \\
\text { /原因 }\end{array}$ & $\begin{array}{l}\text { Purpose } \\
\text { /目的 }\end{array}$ & $\begin{array}{l}\text { Accouding to } \\
\text { /根据 }\end{array}$ & $\begin{array}{l}\text { Direction } \\
\text { /方向 }\end{array}$ & $\begin{array}{l}\text { Condition } \\
\text { /条件 }\end{array}$ \\
\hline & $\begin{array}{l}\text { Concession } \\
\text { /让步 }\end{array}$ & $\begin{array}{l}\text { Besides } \\
\text { /递进 }\end{array}$ & $\begin{array}{l}\text { Conjuncture } \\
\text { /并列 }\end{array}$ & $\begin{array}{l}\text { Except } \\
\text { /除了 }\end{array}$ & & \\
\hline \multirow{2}{*}{$\begin{array}{l}\text { Syntacitc } \\
\text { Relations } \\
\text { (9) }\end{array}$} & $\begin{array}{c}\text { ‘De’ } \\
\text { dependency } \\
\text { /“的”字依存 }\end{array}$ & $\begin{array}{c}\cdots, \text { Shi } \cdots \text { ' }{ }^{\prime} \text { de } \\
/ \cdots \text { 是 } \cdots \text { 的依存 }\end{array}$ & $\begin{array}{l}\text { Connection } \\
\text { /连接依存 }\end{array}$ & $\begin{array}{c}\text { LocationPreposition } \\
\text { /方位词依存 }\end{array}$ & $\begin{array}{l}\text { Tense\&Voice } \\
/ \text { 时态语态 } \\
\text { 依存 }\end{array}$ & $\begin{array}{c}\text { Mood } \\
\text { /语气依存 }\end{array}$ \\
\hline & $\begin{array}{l}\text { Correlative } \\
\text { /关联词依存 }\end{array}$ & $\begin{array}{c}\text { Trend } \\
\text { /趋向动词依存 }\end{array}$ & $\begin{array}{l}\text { Preposition } \\
\text { /介词依存 }\end{array}$ & & & \\
\hline $\begin{array}{l}\text { Special } \\
\text { relaions } \\
(2)\end{array}$ & $\begin{array}{l}\text { Kerne1 word } \\
\text { /核心成分 }\end{array}$ & $\begin{array}{l}\text { Failure } \\
\text { / 依存失败 }\end{array}$ & & & & \\
\hline
\end{tabular}

Table 1: The dependency relation tag set.

\section{The tagging and checking of semantic dependency relations}

\subsection{Texts of corpus}

A part of Tsinghua Corpus (Zhang, 1999) annotated with semantic classes was selected as raw data of our corpus. The texts of Tsinghua corpus come from the news of People's Daily. The selected part consists of about 1,000,000 words, approximately $1,500,000$ Chinese characters. Its domain covers the politics, economy, science, sports, etc. The proportion of different domains is shown in figure 2.

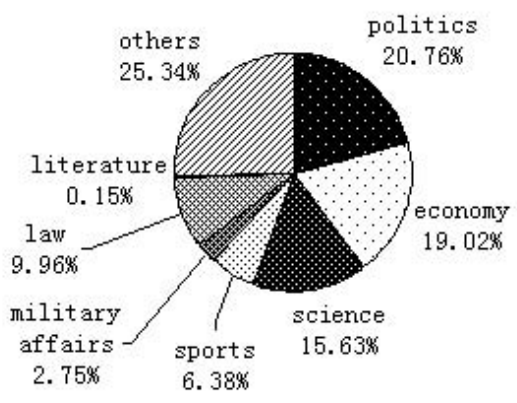

Figure 2: The proportion of texts of different domains

Because Chinese is not written with word delimiters, first the text was segmented into words 
according to the lexicon of 100,000 words. Then each word was tagged with semantic class, whose definition follows Tongyici Cilin (Dictionary of Synonymous Words) (Mei et al., 1983).The semantic classes are organized as a tree, which has three levels. The first level contains 18 classes, the second level contains 101 classes, and the third level contains 1434 classes. These hierarchical semantic classes are helpful to express the superordinate and subordinate information among words.

All the text in Tsinghua Corpus was segmented, tagged and checked manually. Since the corpus was built in 1998, it has been used for several years in the researches on automatic sense tagging and class-based language model. Now, the accuracy of tagging system has reached to $92.7 \%$ (Zhang, 1999).

\subsection{Tagging tools}

A computer-aided tagging tool was developed to assist annotators in tagging semantic dependency relations. To tag a word, annotator only need to select its headword and their relation by clicking mouse. After a sentence has been tagged, the corresponding semantic dependency tree will be displayed to help annotators check the sentence structure.

Two additional functions are also provided in the tool: dependency grammar checking and online reference of HowNet. Dependency grammar checking guarantees that the tagged sentence conforms to four axioms of dependency grammar (Robinson, 1970):

(a) One and only one element is independent;

(b) All others depend directly on some element;

(c) No element depends directly on more than one other

(d) If A depends directly on B and some element $\mathrm{C}$ intervenes between them (in linear order of string), then $\mathrm{C}$ depends directly on $\mathrm{A}$ or $\mathrm{B}$ or some other intervening element.

During annotating procedure, the tool checks whether the tagged relation conforms to dependency grammar, and prompts the grammar errors in time.

On-line HowNet reference facilitates looking up semantic knowledge and helps to ensure the consistency of tagging. Semantic knowledge is more difficult to grasp than syntactic knowledge. Even for annotators majored in linguistics, it is too difficult to grasp all semantic relations of words only after a short-term training. And different opinions about relations will lead to the inconsistency. However, HowNet defines the necessary role frame for verbs frequently used in real world, and these roles can be mapped to our semantic relations, so HowNet has set up a detail annotating manual for us. For example, in HowNet the role frame of the verb “重视” (pay attention to) is defined as \{experiencer, target, cause\}. With basic semantic knowledge, annotators can easily identify the relation between “博士” (doctor) and “重视” (pay attention to) as "experiencer", and the relation between “推广” (popularization) and “重视” (pay attention to) as "target". We integrated the on-line reference of HowNet to the tool, which has been proved in practice to be very helpful in improving the consistency and speed of tagging.

\subsection{Checking}

Our work is the first attempt to annotate semantic dependency relations on a large corpus, and no prior knowledge is available, so the whole corpus is tagged manually. But in checking procedure we have learned some experience and knowledge, which should be used as possible as we can. So we adopt two checking modes. In the first modemanual checking, checkers correct all errors by hand; in second mode-semiautomatic checking, computer-aided checking tool automatically searches for the errors and then human checkers correct them, and it means checkers need to read only about $1 / 3$ or less questionable sentences.

In semiautomatic checking, all the files are scanned automatically to search for three kinds of errors:

1. To check whether the semantic relations conform to the necessary role frame defined by HowNet.

2. To check whether the relations conform to error rules. Some errors frequently occurred during manual checking. For example, the relation between words “再/又”(again) and a verb must be "frequency", but in incorrect sentences it was tagged otherwise. We summarized these errors, and wrote them as rules. 3. To check whether the score of semantic dependency model (equation 1) is below some threshold. A simple semantic dependency model was built on the corpus. Although the 
score of tagged sentence cannot be the criterion of correctness, at least it can show the consistency of a kind of sentences.

$$
P(T)=\prod_{k=1}^{n} P\left(w_{k}, h\left(w_{k}\right), r_{k}\right)
$$

where $n$ is the length of the sentence, $w_{k}$ is the $\mathrm{k}$-th word in the sentence, $h\left(w_{k}\right)$ is the headword to $w_{k}$ with semantic relation $r_{k}$.

The semiautomatic checking interface could prompt some possible errors, but the necessary role frames defined by HowNet may be not complete, the error rules may be not restrict, and the score of semantic structure model may be not credible. The prompted errors may be false, so the decision whether the error is true and how to correct it must be made by human checkers. This is the reason why it is called semiautomatic checking.

The checking procedure consisted of five rounds of selective manual checking and a round of semiautomatic checking. In tagging procedure, we dispatched the raw files to annotators in a group of 10 files. In a round of selective manual checking, one file in every group was selected to check. All corrections were recorded by the checking interface, and the reasons for corrections were explained by the checker. If too many error sentences occurred in the selected file, all files in this group needed correcting by original annotators after referring to the corrected sentences and their explanations.

After four rounds of selective manual checking, most of errors have been corrected, but there were still some files that have not been checked or corrected. We semi-automatically checked all files. Finally, the fifth round of manual checking was taken.

Fourteen graduate studentstook part in annotating, most of them are majored in linguistics. Seven excellent students were elected for checking among annotators, and they were not allowed to check their own files. According to our statistics, the average speed to annotate by hand is about 1.15 hours per 100 sentences; the average speed to check by hand is about 0.25 hours per 100 sentences; and the speed to check half automatically is about 0.08 hours per 100 sentences. In manual checking procedure, there were $50 \%$ of all files that were manually checked, $75.45 \%$ that were turned to the original annotator to correct. (When counting the files corrected by original annotators, if the same group of files were corrected in two rounds, we count them as two groups.) And all files were checked in semiautomatic checking procedure.

\subsection{Congruence}

Under the given annotating manual, consistency is an important criterion to evaluate the corpus. If tagged sentence is independently checked and passed by several experts, the annotation may be credible; otherwise, if some experts do not agree to the annotation, it may be not credible enough. If several experts evaluate tagged sentences independently, the inter-checker agreement is defined as the measure of consistency.

Relation Congruence ( $\mathrm{RCn}$ ) and Sentence Congruence ( $\mathrm{SCn}$ ) are defined. $\mathrm{RCn}$ is the number of relations for which $\mathrm{n}$ judges agreed, divided by the total number of relations, in which $\mathrm{n}$ can be 1 , $2,3 . \mathrm{SCn}$ is the number of sentences for which $\mathrm{n}$ judges agreed, divided by the total number of sentences, in which $\mathrm{n}$ can be $1,2,3$. For example, if three experts take part in evaluating, RC3 is the percentage of the annotated relation that all three experts are agree to one annotation, and $\mathrm{SC} 1$ is the percentage of the annotated sentence for which all three judges' opinions are different from one another.

Before checking, 500 sentences were evaluated by three experts. After checking, 1,400 sentences were evaluated by three experts. In order to balance the coverage and workload of evaluation, another 4,900 sentences were evaluated by two experts. The congruency is shown in table 2 .

\begin{tabular}{|c|c|c|c|}
\hline & RC3 & RC2 & RC1 \\
\hline Unchecked(500) & $90.78 \%$ & $8.65 \%$ & $0.57 \%$ \\
\hline Checked(1400) & $96.24 \%$ & $3.64 \%$ & $0.12 \%$ \\
\hline Checked(4900) & -------- & $97.56 \%$ & $2.44 \%$ \\
\hline & SC3 & SC2 & SC1 \\
\hline Unchecked(500) & $69.20 \%$ & $23.00 \%$ & $7.80 \%$ \\
\hline Checked(1400) & $83.43 \%$ & $14.07 \%$ & $2.50 \%$ \\
\hline Checked(4900) & --------- & $89.10 \%$ & $10.90 \%$ \\
\hline
\end{tabular}

Table 2: the congruency of data before and after checking

The results show that the quality of corpus is improved greatly after checking, and high rela- 
tion/sentence congruency of $96.24 \% / 83.43 \%$ among three experts was satisfactory.

\section{Future works}

Although the tagging task is completed, much further work will be needed. A user-friendly, interactive interface for corpus investigation is needed to search the example sentences and to maintain the tagged data. Inconsistencies still exist in the corpus, and it may become more apparent with time. How to reduce inconsistencies is a challenging problem. The role frame of verbs can to be extracted from the corpus, which could be integrated with HowNet to build a larger database. The correlation frame of nouns, which can represent the order of modifier phrases, can be extracted, too.

More statistical researches could be carried out on the corpus. Researches on Chinese information structure have been carried out on the corpus (You et al., 2002). Auto-tagging the semantic dependency structure of this kind is under going. And we hope the SDN corpus could be exploited in more areas: speech recognition, natural language understanding, machine translation, information extraction, and so on.

\section{Comparison with other corpora}

Our Corpus is compared with other famous corpora for English and Chinese in table 3.

\begin{tabular}{|c|c|c|c|c|}
\hline Corpus & Languge & Content & Scale & Institution \\
\hline SDN & Chinese & $\begin{array}{c}\text { Semantic } \\
\text { dependency }\end{array}$ & $\begin{array}{c}1,000,000 \\
\text { words }\end{array}$ & Tsinghua \\
\hline FrameNet & English & $\begin{array}{c}\text { Frame } \\
\text { Semantics }\end{array}$ & $\begin{array}{c}250,000 \\
\text { sentences }\end{array}$ & Berkeley \\
\hline TreeBank(C) & Chinese & $\begin{array}{c}\text { Phrase } \\
\text { structure }\end{array}$ & $\begin{array}{c}500,000 \\
\text { words }\end{array}$ & UPenn \\
\hline
\end{tabular}

Table 3: Comparison with other corpora

The FrameNet is annotated with semantic knowledge, which emphasizes on describing the frame and scene of several thousands verbs. They first build a frame database, which contains descriptions of each frame of the verbs, and then annotated example sentences of these frames. Unlike FrameNet, we first annotated semantic dependency relations of sentences according to HowNet, and hope to extract frames from the corpus later. FrameNet only described the frame of verbs, while from Semantic Dependency Net the correlation frame of nouns and verbs could be automatically learned by machine.

\section{References}

Collin F. Baker, Charles J. Fillmore, John B. Lowe. 1998. The Berkeley FrameNet Project, Proceedings of the COLING-ACL, Montreal, Canada.

Zhendong Dong and Qiang Dong. 2001. Construction of a Knowledge System and its Impact on Chinese Research, Contemporary Linguistics, 3: 33-44, Beijing.

Chu-Ren Huang and Keh-jiann Chen. 1992. A Chinese Corpus for Linguistics Research. In the Proceedings of the COLING. 1214-1217. Nantes, France

Richard Hudson. 1998. Word Grammars, Dependency and Valency, An International Handbook of Contemporary Research. Edited by Vilmos Agel, Ludwig M. Eichinger, etc. Berlin, Walter de Gruyter.

Tom B. Y. Lai and Changning Huang. 2000. Dependency-based syntactic analysis of Chinese and Annotation of Parsed Corpus. The 38th Annual Meeting of the Association for Computational Linguistics, Hong Kong.

Juanzi Li and Zuoying Wang. 2002. Chinese Statistcal Parser Based on Semantic Dependecies, Tsinghua Science and Technology, 7(6): 591-595.

Mingqin Li, Fang You, Juanzi Li, Zuoying Wang. 2002. Manual of Tagging Semantic Dependency (third Version), Technical Report, Tsinghua University, Department of Electronic Engineering.

Mitchell P. Marcus, Beatrice Santorini, Mary Ann Marcinkiewicz. 1993. Building a large annotated corpus of English: The Penn Treebank. Computational Linguistics, 19(2): 313-330.

Jiaju Mei, Yiming Zhu and YunQi Gao, Yin Hongxiang, Edited. 1983. Tongyici Cilin (Dictionary of Synonymous Words), Shanghai Cishu Publisher.

George A. Miller, Richard Beckwith, Christiane Fellbaum, Derek Gross, and Katherine Miller. 1993. Introduction to WordNet: An On-line Lexical Database, Five papers on WordNet, CSL Report 43, Cognitive Science Laboratory. Princeton University.

Jane J. Robinson. 1970. Dependency Structures and Transformation Rules. Lanuage, 46: 259-285.

Fei Xia, Martha Palmer, Nianwen Xue, Mary Ellen Okurowski, John Kovarik, Fu-Dong Chiou, Shizhe Huang, Tony Kroch, and Mitch Marcus. 2000. Proceedings of the second International Conference on 
Language Resources and Evaluation (LREC 2000), Athens, Greece.

Guowei Yan and Huimin Tan. 1999. Corpus Annotating Mannual Based on HowNet (Jiyu ZhiWang de Yuliao Biaozhu Shouce), Technical Report, the Department of computer science, Hong Kong University of Sience of Techonolgy. http://www.keenage.com

Fang You, Juanzi Li and Zuoying Wang. 2002. An approach Based HowNet for Extracting Chinese Message Structure, Computer Engineering and Applications, 38: 56-58.

Jianping Zhang. 1999. A Study of Language Model and Understanding Algorithm for Large Vocabulary Spontaneous Speech Recognition. Doctor Dissertation, The Department of Electronic Engineering, Tsinghua University, Beijing.

\section{Appendix A. samples from corpus}

Sentence 1: 其中提到东京上野的樱花烂漫的时节

0 其中 1 提到 范围/Scope

1 提到 -1-1 核心成分/Kernel word

2 东京 3 上野 限定/Restrictive

3 上野 8 时节 限定/Restrictive

4 的 3 上野 “的”字依存/“De’ dependency

5 浟花 6 烂漫 描写体/Descriptive

6 烂漫 8 时节 限定/Restrictive

7 的 6 烂漫 “的”字依存/'De’ dependency

8 时节 1 提到 内容/Content

Sentence 2: 在 北京虽也见过天坛公园 自日本移植 的 樱花

0 在 1 北京介词依存/Preposition

1 北京 4 见过 处所/Location

2 虽 4 见过 关联词依存/Correlative

3 也 4 见过 评论/Comment

4 见过 -1-1 核心成分/Kernel word

5 天坛 6 公园 限定/Restrictive

6 公园 11 樱花 限定/Restrictive

7 自 8 日本 介词依存/Preposition

8 日本 9 移植 原处所/LocationIni

9 移植 11 樱花 受事/Patient

10 的 9 移植 “的”字依存/'De’ dependency

11 樱花 4 见过 内容/Content
Sentence 3: 诗集共收入年轻诗人戈麦一百三十多首 代表其各个时期的优秀作品

0 诗集 2 收入 施事/Agent

1 共 2 收入 评论/Comment

2 收入 -1-1 核心成分/Kernel word

3 年轻 4 诗人 描述/Modifier

4 诗人 18 作品 限定/Restrictive

5 戈考 4 诗人 同位语/Appositive

6 - 11 首 数量/Quantity

7 百 6 - 连接依存/Connection

8 三 6 - 连接依存/Connection

$9+6$ - 连接依存/Connection

10 多 6 - 连接依存/Connection

11 首 18 作品 数量/Quantity

12 代表 18 作品 关系主体/Relevant

13 其 15 时期 限定/Restrictive

14 各个 15 时期 限定/Restrictive

15 时期 12 代表 类指/Isa

16 的 12 代表 “的”字依存/'De’ dependency

17 优秀 18 作品 描述/Modifier

18 作品 2 收入 受事/Patient

Sentence 4: 相信 会 得到 喜爱 中国 传统 文化 的人士 青崃

0 相信 -1-1 核心成分/Kernel word

1 会 2 得到 评论/Comment

2 得到 0 相信 内容/Content

3 喜爱 8 人士 经验者/Experiencer

4 中国 6 文化 限定/Restrictive

5 传统 6 文化 限定/Restrictive

6 文化 3 喜爱 目标/Target

7 的 3 喜爱 “的”字依存/'De’ dependency

8 人士 9 青睐 限定/Restrictive

9 青睐 2 得到 占有物/Possession

Sentence 5: 在如镜似烐的滩涂上:

0 在 6 滩涂介词依存/Preposition

1 如 6 滩涂 关系主体/Relevant

2 镜 1 如 参照体/Contrast

3 似 1 如 连接依存/Coordination

4 毯 3 似 参照体/Contrast

5 的 1 如 “的”字依存/'De' dependency

6 滩涂 -1-1 核心成分/Kernel word

7 上 6 滩涂 方位词依存/LocationPreposition 